\title{
Vorläufiges über eine neue Gattung und Art von den Fidschi-Inseln.
}

Von Dr. Ant. Reichenow.

Trichocichla Rchw. n. g. Timeliinarum.

Rostrum elongatum, basi depressum, apice compressum, ante apicem crena praeditum, vibrissis rictus duabus brevibus. Uropygium valde plumosum. Ala e rotundatae, remigibus IV $-V$ sive IV-VI aequalibus, longissimis, tertia sextae s. septimae aequali, secunda novae s. decimae aequali, prima dimidium longissimae parum superante, rem. secundariis quam primariis paulo brevioribus. Ca uda valde gradata, rectricibus XII, extimis mediarum dimidium parum superantibus. Pedes validi, tarso lamina cornea continua vestito.

Typus: Trichocichla rufa Rchw. n. sp.: Notaeo toto obscure rufo, uropygio dilutiore; remigibus et tectricibus nigrofuscis, obscure rufo-limbatis; stria superciliari albida, postice rufescente; gula alba; capitis lateribus obscure rufis, oculo plumulis albis circumdato; colli lateribus et pectore dilute rufescentibus, pectore et ventre mediis fere albidis; hypochondriis, crisso et subcaudalibus obscure rufis; subalaribus nigricantibus, rufescente albido-limbatis; pedibus albidis; rostro fusco. Long. tot. c. 200 , álae 78 , caudae 85-90, rostri a. fr. 18, rostri a rictu $20-22$, tarsi $30-31$, rectricium extimarum et mediarum intervallum $35-40 \mathrm{~mm}$. Hab. Viti-Levu.

\section{Nachrichten.}

\section{Berichtigungen.}

Auf S. 80 (Anmerkung zu Cygnus immutabilis) ist zu setzen: "Der alte Unveränderliche Schwan unterscheidet sich von dem alten Höckerschwan." u. s. w.

Auf S. 86 unter 5 zweiter Absatz die Worte nund hinten" $z \mathfrak{u}$ streichen. Auf S. 150 Zeile 10 v. u. die Worte "beide Geschlechter" zu streichen. Pelecanis.

Auf S. 165 ist in der Ueberschrift "Pelecanus" zu setzen statt streichen.

Auf S. 166. Zeile 9 v. o. ist das Komma hinter der Parenthese zu

Verlags - Anzeige.

A. Friedländer \& Sohn, Berlin NW. Carlstrasse 11.

Soeben erschien :

\section{Nomenclator \\ Musei Heineani Ornithologici. \\ Verzeichniss der Vogel-Sammlung \\ des \\ Königlichen Oberamtmanns Ferdinand Heine \\ auf Klostergut St. Burchard vor Halberstadt \\ herausgegeben ron}

Ferdinand Heine und Anton Reichenow

auf Kloster Hadmersleben.

Ein Band in Imp. 8 mit Heine's Portrait. Preis 10 Mark. 